\title{
Multivariate Analysis of Spider Diversity in Agricultural, Horticultural and Silvicultural Ecosystems and their Relation to Subtropical Climatic Conditions
}

Jyotim Gogoi ( $\sim$ jyotimgogoi@gmail.com )

Central Agricultural University

Kennedy Ningthoujam

Central Agricultural University

\section{Research Article}

Keywords: Principal Component Analysis (PCA), Correspondence Analysis (CA), Biplot, Eigenvalue, Cluster

Posted Date: July 1st, 2021

DOl: https://doi.org/10.21203/rs.3.rs-640078/v1

License: (c) (1) This work is licensed under a Creative Commons Attribution 4.0 International License.

Read Full License 


\title{
Multivariate Analysis of Spider Diversity in Agricultural, Horticultural and Silvicultural Ecosystems and their relation to Subtropical Climatic Conditions
}

Gogoi, J. ${ }^{1}$ and Ningthoujam, K. ${ }^{2}$

\section{School of Crop Protection}

\section{College of Post-Graduate Studies in Agricultural Sciences}

Central Agricultural University, Meghalaya-793103

2 Assistant Professor (Entomology)

School of Crop Protection

College of Post-Graduate Studies in Agricultural Sciences

Central Agricultural University, Meghalaya-793103

\begin{abstract}
Spiders are the Arthropod and belong to the Phylum: Arthropoda, Class: Arachnida, Order: Araneae. Spiders totally depend on predation of small insects and other animals and have important role in the structure of communities and food webs both as an individual numbers and as an energy consumer.. Hence, documentation of spiders gives information about biodiversity of ecosystem in a particular geographical area. Totally arthropods belonged to 14 orders and 85 Nos. of different families. To study the similarity between two groups in species, family and ordinal level is used Agglomerative Hierarchical Clustering (AHC). Principal Component Analysis (PCA) and Correspondence Analysis (CA) were evaluated to understand the arthropod population dynamics and habitat specific occurrence of spiders in different ecosystem Viz., Silvicultural, Horticultural and Agricultural ecosystem. To correlate the weather parameters with spider population we used Pearson correlation, regression line, Redundancy Analysis (RDA) and Canonical Coefficient Analysis (CCA). Correlation analysis showed arthropod population positively correlated to maximum and minimum temperature and evening relative humidity and negatively correlated to morning relative humidity and rainfall. The eigenvectors at generic level was found maximum in horticultural ecosystem (0.591) followed by silvicultural $(0.581)$, maize $(0.407)$, rice $(0.329)$ and potato ecosystem $(0.183)$ in factor $(\mathrm{F} 1)$. The asymmetric CA row and column plot in generic level suggested that the genus Tylorida, Cyclosa, Neoga, Phintella, Hamadruas etc., Ruborridion, Clubiona, Guizygiella, Callilepis etc., Dorassodes, Nihohimea, Philodromus, Castineria, Dolomedes, Olios etc., Epocilla, Sosticus, Evarcha etc., Myrmarache, Larinis, Thaina Mesida, Gasteracantha, Zelotes etc. showed affinity towards maize, rice, silvicultural, potato and horticultural ecosystems respectively. In case of weather perimeter with relation to arthropod population RDA showed that Arachnids families viz., Lycosidae, Thomisidae, Theridiidae, Tetraganthidae etc are closely associated with maximum temperature in silvicultural and horticultural ecosystems.
\end{abstract}

Key words: Principal Component Analysis (PCA), Correspondence Analysis (CA), Biplot, Eigenvalue, Cluster 


\section{Introduction}

Biological diversity is the first terminology used by biologist Lovejoy in the year 1890 to describe numbers of species. E. O. Wilson first used the term 'Biodiversity' in written form in the proceedings of U.S. Strategy Conference on Biological Diversity (1981) held on Washington D.C. (Swingland, 2001). According to Delong 1996 "Biodiversity is an attribute of an area and specifically refers to the variety within and among living organisms, assemblages of living organisms, biotic communities, and biotic processes, whether naturally occurring or modified by humans. Muhammad and Ahmed (2014) studied the seasonal abundance of soil arthropods in relation to meteorological and edaphic factors in the agroecosystems viz., sugarcane, cotton, wheat, alfalfa and citrus orchards of Faisalabad, Punjab, Pakistan. They used Bray-Curtis cluster analysis to study the soil arthropod based on similarity of abundance and found 4 different similarity cluster groups: first cluster comprised of Collembola, Hymenoptera, Acarina, and Myriapoda ( $>10 \%)$, second cluster comprised of Orthoptera, Coleoptera, and Araneae ( $>5 \%)$, third cluster those of Hemiptera, Dermaptera, and Diptera $(>1 \%)$ and fourth cluster comprised of Blattaria, Diplura, Isoptera, and Lepidoptera $(\approx 0 \%)$. Schuldt et al. (2008) evaluated the spider diversity in 3 different deciduous forest stands viz.,one-species stands (Beech, Fagus sylvatica), three-species stands (Beech, F. sylvatica, Ash, Fraxinus excelsior and Lime, Tilia cordata) and five-species stands (Beech, Ash, Lime, Hornbeam, Carpinus betulus and Maple, Acer pseudoplatanus). Mean species richness was found to be significantly low in one-species stands. Shannon-Wiener index and Evenness index were found maximum in one-species stand and minimum in five-species stands. In case of forest floor eigenvalues of Principle component analysis (PCA) and Redundancy analysis (RDA) as well as the distribution of plots within the ordinations differed considerably, even though Monte Carlo testing of axes was significant. RDA for pitfall trap showed negative to community structure, litter depth and amount of beech litter. Pinzon et al. (2011) evaluated the spider diversity in boreal white spruce (Picea glauca) forest. The species turnover was quantified by Whitaker's beta-diversity $(\beta \mathrm{w})$ measure between horizontal and vertical turnover. The RDA analysis using Hellinger transformed abundances $(\lambda)$ showed that spider assembling in mid-over story was maximum than to that of the ground and branch structural features. Bouseksou et al. (2015) studied the ecology of spider fauna of two ecosystems of wheat and rape seed from Mitidja plain, Algeria. A total of 2036 nos. of individual were collected comprising of 18 families, 52 genera and 81 species. The habitat preferences of abundant species were evaluated by non-parametric analysis done by Mann-Whitney U-test and Correspondence analysis (CA). Rosa et al. (2019) studied the diversity of soil spiders in land use and management systems in Santa Catarina, Brazil and use principal component analysis to evaluate habitat specific occurrence of spider in native forest, eucalyptus reforestation, pasture, crop-livestock integration, and no-tillage crop. They evaluated soil physical, chemical, and microbiological attributes and the abundance and diversity of spider families, collected by soil monolith and soil traps. A total of 448 spiders were captured, 152 in winter and 296 in summer, distributed in 24 families and 52 species/morphospecies. There was a seasonality effect related to the land use systems and the highest Shannon-Wiener diversity index was recorded in the native forest in both sampling periods. Most families of spiders have a direct dependence on soil physical and chemical properties, such as microporosity, exchangeable aluminum, calcium, magnesium, and potassium during the winter. Organic matter, nitrogen, $\mathrm{pH}$ in water, weighted average diameter, soil density, and microbial biomass carbon exhibited dependence during the summer. Vegetation type and soil management are the factors that seem to affect most the occurrence of spiders. For clear cut understanding three different ecosystems were selected viz., Silvicultural ecosystem (Pine trees) composed with perennial trees and herbs with no human intervention having stable habitat structure, Horticultural ecosystem (Citrus plantation) composed with perennial crops and herbs but human intervention occurs in a particular periods of time having moderately stable habitat structure and 
Agricultural ecosystem (Maize, Potato and Rice plantation) composed with seasonal crops but human intervention occurs frequently in short period of time having unstable habitat structure. For detail evaluation and to correlate between spider population and different ecosystems as mentioned we employ different multivariate analysis techniques such as Agglomerative hierarchical clustering (AHC), Principal component analysis (PCA) and Correspondence analysis (CA). In this paper we also evaluated the effectiveness and efficiency of different multivariate techniques. On the other hand to correlate the weather parameters with spider population we used Redundancy Analysis (RDA) and Canonical Coefficient Analysis (CCA). Correlation analysis showed arthropod population positively correlated to maximum and minimum temperature and evening relative humidity and negatively correlated to morning relative humidity and rainfall.

\section{Materials and methods}

The investigation was carried out at Experimental farm of CPGSAS, CAU, Umiam during the time period 02 July, 2019 to 11 February, 2020. Weekly observation was taken from 1st standard meteorological week (SMW) i.e. $27^{\text {th }}$ SMW of July, 2019 onwards till $06^{\text {th }}$ SMW of February, 2020. The sample collection was done in 3 ecosystems and took an area about $(10 \times 10) \mathrm{m}^{2}, 100 \mathrm{~m}^{2}$ Viz., Agricultural ecosystems (Maize, Zea mays L.; Potato, Solanum tuberosum L. and Rice, Oryza sativa L.), Horticultural (Citrus, Citrus limon L. and Turmeric, Curcuma longa L. agro ecosystem) and Silvicultural (Native forest dominated by Pine, Pinus insularis Endl. trees) ecosystem. Spiders were collected from 3 ecosystems without damaging the crops/plants using hand, aspirators, sweep nets, Inverted umbrella, pitfall trap and rubbish traps. The agricultural and horticultural systems present inside the university campus and permission was taken from college authority to conducting the experiment work. For the collection of silvicolous spider permission taking from the department of Botanical survey of India, Shillong, Meghalaya.

\subsection{Sampling methods}

Collection of arthropods was done through hand picking, using aspirators, sweep nets, Inverted umbrella, pitfall trap and rubbish trap. For carrying out arthropods collection, the plot was divided into 100 quadrats measuring $10 \mathrm{~m} \times 10 \mathrm{~m}$. Spiders and insects from rocks, logs, debris and bark of the trees were collected by hand picking and active searching.

\subsection{Preservation of Arthropods}

Spiders were killed using chloroform and the specimens were preserved in $5 \mathrm{ml}$ glass vials with 70 per cent ethyl alcohol (70 parts of 100 per cent alcohol +30 parts of distilled water) which was used by Joseph and Premila (2016). Khan (2009) and Khan and Rather (2012) also followed the standard protocol for preserving the very small spider specimens and the juvenile spiders in Oudeman's fluid.

\subsection{Identification of Arthropods}

The most common and important arthropod species were identified to the lowest possible taxon. Identification was done based on established taxonomic keys and literature (Tikader and Bal, 1980; Tikader, 1987; Barrian and Litsinger, 1995: Khan and Khan, 2011). Cataloguing and documentation was done using images and photographs. Spiders were identified by Dr. Manju Siliwal, Arachnologist at Wildlife Institute of India, Dehradun. 


\subsubsection{Multivariate statistics for relationship between arthropods and ecosystems}

\subsubsection{Agglomerative hierarchical clustering (AHC)}

Clustering is a function of multidimensional analysis that consists in partitioning a collection of variables. First used by Polish ecologist Kulczynski (1928) quite different from modern clustering known as seriation. AHC is also designated as Hierarchical agglomerative clustering (HAC). To study presence-absence of species, species abundances, similarity and dissimilarity among species and evaluation of indicator species the complete linkage agglomerative hierarchical clustering is widely accepted. Complete linkage AHC also known as furthest neighbour sorting and first proposed by Sorensen (1948). In this clustering method the fusion of two clusters depends on the most distant pair of objects instead of the closest. Thorrington-Smith (1971) used complete linkage AHC to analysis of association among species of phytoplankton and Legendre and Chodorowski (1977) use to analysis of relative abundance of zooplanktons. The linkage between clusters given by relation Gc.

\subsubsection{Principal component analysis (PCA)}

Principal Component Analysis (PCA) is a multivariate statistical technique that uses orthogonal transformation to convert a set of correlated variables into a set of orthogonal, uncorrelated axes called principal components. Many times ecologist dealing with a large multivariate ecological dataset dealing with different factors Viz., environmental parameters, genetic variability, community structure etc. (Legendre and Chodorowski, 1997).

\subsubsection{Correspondence analysis (CA)}

Correspondence analysis (CA) allows ecologist analysed large multivariate dataset into a tow dimensional space with direct comparison of respective variables which is almost similar to Principal component analysis (PCA). CA commonly known as contingency table analysis (Fisher, 1940). CA was developed by several authors independently Hirschfeld (1935), Fisher (1940) etc. and first applied in ecology by Roux and Roux (1967), Hatheway (1971), Ibanez and Seguin (1972) and Hill (1973) to analysed habitat specific occurrence (site $\times$ species contingency table) of species. First method of CA was two-way contingency table with rows and columns. Each cells of contingency table represent frequencies. Common application of CA in ecology is to analysis of community composition i.e. presence-absence or abundance of species in sampling sites (Legendre and Chodorowski, 1997).

\subsubsection{Multivariate statistics for relationship between arthropods and environment}

\subsubsection{Redundancy analysis (RDA)}

First Canonical redundancy analysis defined by Rao (1964) after that it was rediscovered by Wollenberg (1977) and coined the term Redundancy analysis (RDA). RDA is the direct extension of multiple regressions to the modelling of multivariate response data. The evaluation based on asymmetric response and explanatory variable $\mathrm{Y}$ ( $\mathrm{n} x$ p) and $\mathrm{X}(\mathrm{n} \times \mathrm{m})$. RDA ordination axis obtained from PCA data matrix by plotting the $\mathrm{Y}$ variables to $\mathrm{X}$ through multivariate leaner regression and utilise Euclidian distance among objects. RDA is commonly used to control in leaner effect, separate the outcome of a single explanatory variable, evaluation of related species, construction of MANOVA, construction of Principal response curve (PRC) and screening of explanatory factors. RDA was used by ecologist to analysed structure of arthropod communities and seasonal dynamics by Tim and Roth (2008), Schuldt $e t$ al. (2008), Samu et al. (2014) and Rosa et al. (2019). 


\subsubsection{Canonical correlation analysis (CCA)}

Canonical correlation analysis also designated as CCorA. CCA is asymmetric ordination method first proposed by TerBraak (1986). CCA was utilised to analysed to study spider community and association with environmental factors by Aart and Smeenk-Enserink (1975), TerBraak (1986), De'ath (2002), Maxim et al. (2005), Forbanka and Niba (2013) and Muhammad and Ahmed (2014). The Statistic of CCA is derived from RDA but instead of $\mathrm{Y}, \mathrm{Q}^{-}$matrix is used for computation of response matrix and diagonal matrix of row weight $\mathrm{D}\left(\mathrm{P}_{+\mathrm{i}}\right)$ is used for computation of regression. The common uses of CCA are study of species spatial distribution with environmental variables (Cadoret et al., 1995), Palaeolimnological reconstruction (Birks et al., 1990), Palaeoecology, Limnology and Palaeolimnology (Birks et al., 1998).

\section{Results}

\subsection{Arachnida}

Totally 4023 arthropods were collected from silvicultural, horticultural and agricultural ecosystem which belonged to 14 orders and 85 Nos. of different families. In familial level maximum diversity was found in class Insecta composed of 66 Nos. of family and 186 Nos. of genera and class Arachnida composed of 19 Nos. of family and 67 Nos. of genera. In ordinal level maximum diversity was found in class Insecta composed of 13 Nos. of family and class Arachnida composed of 1 Nos. of family. Under Araneae most individuals belonged to the family Araneidae (1456) followed by Tetragnathidae (432), Lycosidae (392), Salticidae (345), Ganophosidae (190), Theridiidae (120), Oxyopidae (111), Linyphiidae (82), Zodariidae (47), Thomisidae (35), Corinnidae (19), Clubionidae (17), Cheiracanthiidae (11), Sparassidae (9), Mimetidae (8), Pisauridae (8), Philodromidae (6) and Pholcidae (1). Majority of individuals under family Araneidae were of the genus Cyclosa, Argiope and Neoscona while under family Lycosidae, Tetragnathidae, Salticidae and Gnaphosidae the genus Pardosa, Mesida, Plexippus and Haplodrassus were the most abundant genus found respectively. On the other hand for individual ecosystem maximum diversity were found in silvicultural ecosystem (18 Nos. family) followed by horticultural (13 Nos. family), rice (11 Nos. family), maize (4 Nos. family) and potato (4 Nos. family) ecosystem. In species level maximum diversity found in Neoscona (Aranidae) followed by Cyclosa (Aranidae), Argiope (Aranidae), Pardosa (Lycosidae) (Gogoi and Nigthoujam 2021).

\subsection{Multivariate analysis of relationship between arthropods and ecosystems}

\subsubsection{Variation of Arthropods based on Agglomerative hierarchical clustering (AHC)}

Cluster analysis starts with a matrix giving the similarity between each pair of species, families and orders. The similarity between two groups in a matrix is combined to form a single cluster. The analysis proceeds by successively clustering similar groups until all are combined in a single dendrogram. This is not directly evaluating beta diversity but it is generally used to study the presence or absence of different communities. It is used to identify the specific groupings present in a population in a community.

\subsubsection{Sivicultural ecosystem}

Analysis based on species, familial and ordinal level of Araneae from silvicultural ecosystem showed a distinct variation in similarity groupings. In silvicultural ecosystem, the Araneae formed 3 clusters comprising of 98 numbers of species which shows variance decomposition for the optimal classification within the class $95.67 \%$ and 
between the classes $4.33 \%$ with respect to total class variance $100.00 \%$ (Fig. 1.1). In silvicultural system, maximum distance between the central objects was seen in species Drassodes lutiscens (1.803) followed by Neoscona vigilans (1.462) and Neriene sundaica (0.00). Analysis showed the species Drassodes lutiscens with class object 51, sum of class weight 51, class variance 20.165, minimum class distance to centroid 0.971 , average class distance to centroid 3.576 and maximum class distance to centroid 12.553 (Table 1).

\subsubsection{Horticultural ecosystem}

At species level the araneofauna formed 3 clusters composed of 63 species which showed variance decomposition for the optimal classification within the class $90.49 \%$ and between the classes $9.51 \%$ with respect to total class variance $100.00 \%$ (Fig. 1.2). In horticultural system, maximum distance between the central objects was observed in species Cyclosa insulana (5.038) followed by Pardosa sumatrana (2.650) and Araneus mitificus (0.00). Cluster evaluation revealed the species Cyclosa insulana with class object 28, sum of class weight 28, class variance 63.587, minimum class distance to centroid 1.957, average class distance to centroid 7.227 and maximum class distance to centroid 14.723 (Table 1).

\subsubsection{Maize ecosystem}

In maize ecosystem, at species level the araneofauna formed 3 clusters composed of 63 species which showed variance decomposition for the optimal classification within the class $88.98 \%$ and between the classes $11.02 \%$ with respect to total class variance $100.00 \%$ (Fig. 1.3). In maize system, maximum distance between the central objects was observed in species Cyclosa insulana (4.244) followed by Oxyopes bimanicus (2.958) and Araneus mitificus (0.00). Cluster evaluation related the species Cyclosa insulana with class object 27, sum of class weight 27, class variance 65.430 , minimum class distance to centroid 1.953, average class distance to centroid 7.370 and maximum class distance to centroid 14.604 (Table 2).

\subsubsection{Potato ecosystem}

Analysis based on species level of araneofauna of potato ecosystem showed a distinct variation in similarity groupings represented in the Figure *. In potato ecosystem, the arachnids formed 3 clusters comprising of 14 numbers of species which shows variance decomposition for the optimal classification within the class $71.35 \%$ and between the classes $28.65 \%$ with respect to total class variance $100.00 \%$ (Fig. 1.4). In potato system shows maximum distance between the central objects in species Storena cyanea (2.236) followed by Acanthinozodium sp. (2.000) and Cheriacanthium sp. (0.00). Analysis showed the species Storena cyanea with class object 7, sum of class weight 7, class variance 3.158 , minimum class distance to centroid 0.749 , average class distance to centroid 1.543 and maximum class distance to centroid was 2.744 respectively (Table 2 ).

\subsubsection{Rice ecosystem}

In rice ecosystem, at species level the araneofauna formed 3 clusters composed of 36 species which showed variance decomposition for the optimal classification within the class $94.59 \%$ and between the classes $5.41 \%$ with respect to total class variance $100.00 \%$ (Fig. 1.5). In rice system shows maximum distance between the central objects in species Neoscona mukerjei 1 (4.822) followed by Argiope pulchella (3.354) and Argiope sp. (0.00). Cluster evaluation revealed the species Neoscona mukerjei 1 with class object 9, sum of class weight 9, class variance 20.451, 
minimum class distance to centroid 1.604, average class distance to centroid 3.808 and maximum class distance to centroid 7.996 (Table 2).

\subsubsection{Principal component analysis (PCA)}

The principal component analysis showed the variation of collection data set of Arachnids population in 5 different vegetation types Viz., silvicultural, horticultural, maize, potato and rice ecosystem (Fig. $2.1 \&$ 2.2). The ordination plot explains the occurrence of Arachnids in generic and familial level at observed ecosystems, in generic level PCA biplot explained total $60.89 \%$ of variation in which factor F1/PC1 and factor F2/PC2 explained $39.81 \%$ and $21.71 \%$ and in familial level PCA biplot explained total $83.30 \%$ of variation in which factor F1/PC1 and factor F2/PC2 explained $61.82 \%$ and $21.48 \%$ of variation respectively. The eigenvalues in first and second axis are 1.959 and 1.085 represented in generic level. In familial level eigenvalues are 3.091 and 1.074 in first and second axis (F1/F2) (Table 2.2).

The eigenvectors at generic level was found maximum in horticultural ecosystem (0.591) followed by silvicultural (0.581), maize (0.407), rice (0.329) and potato ecosystem (0.183) in factor (F1) (Table 4.2). The eigenvectors at familial level was found maximum in horticultural ecosystem (0.539) followed by silvicultural (0.517), maize (0.464), rice (0.444) and potato ecosystem (0.172) in factor (F1). Spearman correlation between variables (genus) and Factors (Observed ecosystems) was found maximum in horticultural (0.827) and minimum in potato ecosystem (0.256) in first axis factor (F1) (Table 2.1). Spearman correlation between variables (family) and Factors (Observed ecosystems) was found maximum in horticultural (0.948) and minimum in potato ecosystem (0.303) in first axis factor (F1).

In correlation circle indicating that Arachnids are closely related in horticultural and silvicultural ecosystems in generic and familial level in case of potato maize and rice ecosystem the arachnids are found to be distantly related. In generic level the genus Haplodrassus, Pardosa, Plexipus and Epocilla, Evarcha, Ganophosa, Sosticus, Storena, Nephila, Lecauge, Araneus, Tetraganatha, Lycosa, Oxyopes, Neoscona and Cyclosa are found to unique and distinctly positioned in observation by plot and in familial level Zodariidae, Salticidae, Ganophosidae, Lycosidae, Cheriacanrhiidae, Tertragnathidae and Araneidae are found to unique in observation biplot (Fig. 2.3 \& 2.4). Same results are found in loading vectors in generic and familial level in the Figure $2.3 \& 2.4$.

\subsubsection{Correspondence analysis (CA)}

The correspondence analysis showed the variation of collection data set of Arachnids population in 5 different vegetation types Viz., silvicultural, horticultural, maize, potato and rice ecosystem. The ordination plot explains the occurrence of Arachnids in generic and familial level at observed ecosystems, in generic level CA asymmetric row plot explained total $67.26 \%$ of variation in which CA axis 1 and CA axis 2 explained $37.47 \%$ and $29.79 \%$ and in familial level asymmetric row plot explained total $84.91 \%$ of variation in which factor CA axis 1 and CA axis 2 explained $47.80 \%$ and $37.11 \%$ of variation respectively. The eigenvalues and inertia in first and second axis are $0.381,37.474 \%$ and $0.303,29.785 \%$ represented in generic level. In familial level eigenvalues and percentage inertia are $0.164,47.797 \%$ and $0.127,37.113 \%$ in first and second axis (F1/F2) (Table $3.1 \& 3.2)$.

Squired distances from origin in column plot at generic level was found highest in potato ecosystem (7.437) followed by rice (1.473), maize (1.447), horticultural (0.497) and silvicultural ecosystem (0.360). In familial level squired distances from origin in column plot was ranged between 0.063-3.399 in 5 observed ecosystems. The range of standard coordinates was found between -1.534 to 1.845 at generic level and in familial level it was found 
highest potato ecosystem (4.420) and lowest in maize -1.368 in respects to F1 axis. In case of contribution column at generic level was found highest in horticultural ecosystem in F1 axis (Table 3.2).

The asymmetric row and column plot in generic level suggested that the genus Tylorida, Cyclosa, Neoga, Phintella, Hamadruas etc., Ruborridion, Clubiona, Guizygiella, Callilepis etc., Dorassodes, Nihohimea, Philodromus, Castineria, Dolomedes, Olios etc., Epocilla, Sosticus, Evarcha etc., Myrmarache, Larinis, Thaina Mesida, Gasteracantha, Zelotes etc. showed affinity towards maize, rice, silvicultural, potato and horticultural ecosystems respectively (Fig. $3.1 \& 3.2$ ). The asymmetric row and column plot in familial level suggested that the family Cheiracanthiidae, Zodariidae, Pasauridae, Philodromidae, Pholcidae, Corinnidae, Salatcidae, Ganophosidae etc., showed a distinctive relation to Silviculture, horticultural and potato ecosystems. The family Linyphiidae, Aranidae, Tetraganthidae, Clubionidae, Mimentidae, Oxyopidae, Uloboridae etc., showed a relation to maize and rice ecosystems respectively (Fig. $3.3 \& 3.4$ ).

\subsection{Multivariate analysis of relationship between arthropods and environmental parameters}

\subsubsection{Redundancy Analysis (RDA):}

The Redundancy analysis (RDA) showed the relationship between Arthropod population and environmental parameters in silvicultural, horticultural, maize, potato and rice ecosystem. The RDA ordination plot explains the occurrence of Arthropods in familial and ordinal level at observed ecosystems, in familial level RDA biplot explained total $87.19 \%$ of variation in which axis F1 and axis F2 explained $56.46 \%$ and $30.73 \%$ and in ordinal level RDA biplot explained total $99.27 \%$ of variation in which axis F1 and axis F2 explained $87.16 \%$ and $12.11 \%$ of relation between arthropod population and environmental parameters respectively. The eigenvalues and percentages of inertia in first and second axis are 8.619 and 4.691 represented in familial level (Table 4.1). In ordinal level eigenvalues and total percentages of inertia are 8.888 and 1.235 in first and second axis (F1/F2). The canonical coefficient was found maximum in maximum temperature (4.262) followed by minimum temperature (3.132), relative humidity (evening) (3.122), relative humidity (morning) (0.888) and rainfall (-6769) in ordinal level. Redundancy analysis (RDA) indicating that Arachnids families viz., Lycosidae, Thomisidae, Theridiidae, Tetraganthidae etc are closely associated with maximum temperature in silvicultural and horticultural ecosystems. In rice ecosytem the families such as Clubionidae, Oxyopidae, Ulboridae and Mimetidae are strongly associated with morning relative humidity (Fig. $4.1 \& 4.2$ ).

\subsubsection{Canonical Correlation Analysis (CCA)}

\subsubsection{Silvicultural ecosystem}

The Canonical Correlation Analysis (CCA) showed the relationship between Arthropod population and environmental parameters in silvicultural ecosystem in familial and ordinal level with 8 Nos. of sampling periods July to February. The CCA ordination plot explains the occurrence of Arthropods in familial and ordinal level in silvicultural ecosystems, in familial level CCA biplot explained total $83.07 \%$ of variation in which CCA axis 1 and CCA axis 2 explained $73.07 \%$ and $10.00 \%$ and in ordinal level CCA biplot explained total $74.43 \%$ of variation in which CCA axis 1 and CCA axis 2 explained $56.22 \%$ and $18.20 \%$ of relation between arthropod population and environmental parameters respectively (Table 4.2). Canonical Correlation Analysis (CCA) map indicating that Arachnids families Lycosidae, Pholcidae, Zodariidae and Corinnidae etc. are closely associated with maximum temperature, Araneidae, Theridiidae, Linyphiidae and Salticidae associated with morning RH. The family Cheiracanthiidae, Clubionidae Philodromidae and Sparassidae are associated with evening RH, rainfall and minimum 
temperature in familial level (Fig. 5.1). In ordinal level, orders Isoptera and Lepidoptera strongly associated with maximum temperature and evening RH, Odonata and Hemiptera associated with rainfall. The orders Ephimeroptera and Hymenoptera showed positive relationship towards environmental parameters minimum temperature and morning RH. The orders Dermeptera, Neuroptera, Dictyoptera, Orthoptera, Coleoptera etc. did not show any relationship to environmental parameters (Fig. 5.2)

\subsubsection{Horticultural ecosystem}

The Canonical Correlation Analysis (CCA) showed the relationship between Arthropod population and environmental parameters in horticultural ecosystem in familial and ordinal level with 8 Nos. of sampling periods July to February. The CCA ordination plot explains the occurrence of Arthropods in familial and ordinal level in horticultural ecosystems, in familial level CCA biplot explained total $92.95 \%$ of variation in which axis F1 and axis F2 explained $79.28 \%$ and $13.67 \%$ and in ordinal level CCA biplot explained total $94.43 \%$ of variation in which axis F1 and axis F2 explained $64.02 \%$ and $30.41 \%$ of relation between arthropod population and environmental parameters respectively (Table 4.3). Canocical Correlation Analysis (CCA) map indicating that Arachnids families Lycosidae, Clubionidae and Corinnidae etc. are closely associated with rainfall and evening RH, Salticidae and Thomisidae associated with morning RH and rainfall. The family Cheiracanthiidae and Zodariidae are associated with maximum temperature in familial level. The families Oxyopidae, Theridiidae, Linyphiidae, Araneidae and Tetraganthidae did not showed any relationship towards environmental parameters (Fig. 5.3). In ordinal level, orders Isoptera and Araneae are strongly associated with maximum temperature, Hemiptera associated with rainfall. The orders Lepidoptera and Coleoptera showed positive relationship towards environmental parameters maximum temperature (Fig. 5.4).

\section{Discussion}

\subsection{Multivariate analysis of relationship between arthropods and ecosystems}

\subsubsection{Variation of Arthropods based on dendrogram analysis}

Muhammad and Ahmed (2014) studied the seasonal abundance of soil arthropods in relation to meteorological and edaphic factors in the agroecosystems Viz., sugarcane, cotton, wheat, alfalfa and citrus orchards of Faisalabad, Punjab, Pakistan and used Bray-Curtis cluster analysis to study the soil arthropod based on similarity of abundance and found 4 different similarity cluster groups first cluster comprised of Collembola, Hymenoptera, Acarina, and Myriapoda ( $>10 \%)$, second cluster composed of Orthoptera, Coleoptera, and Araneae ( $>5 \%)$, third cluster Hemiptera, Dermaptera, and Diptera $(>1 \%)$ and fourth cluster composed of Blattaria, Diplura, Isoptera, and Lepidoptera $(\approx 0 \%)$.

Saranya et al. (2019) who studied the diversity of predatory spider fauna in maize ecosystem used dendrogram analysis to evaluate similarity index of predatory spider families. The six spider families formed one clusters and genus formed three clusters with 25\% similarity. Sidclay et al, 2010 used dendrogram analysis to study guilds in Neotropical spiders (Arachnida: Araneae). George et al. (1999) used similarity clustering to study guild structure in major crops Viz., peanut, alfalfa, soybean, rice, corn, cotton, sugar and sorghum. The six spider families formed one clusters and genus formed three clusters with 25\% similarity. Sidclay et al. (2010) used dendrogram analysis to study guilds in Neotropical spiders (Arachnida: Araneae). George et al. (1999) used similarity clustering to study guild structure in major crops viz., peanut, alfalfa, soybean, rice, corn, cotton, sugar and sorghum. 


\subsubsection{Principal component analysis (PCA)}

The ordination plot explains the occurrence of Arachnids in generic and familial level at observed ecosystems, in generic level PCA biplot explained total $60.89 \%$ of variation in which factor F1/PC1 and factor F2/PC2 explained $39.81 \%$ and $21.71 \%$ and in familial level PCA biplot explained total $83.30 \%$ of variation in which factor F1/PC1 and factor F2/PC2 explained $61.82 \%$ and $21.48 \%$ of variation respectively. In correlation circle in generic level the genus Haplodrassus, Pardosa, Plexipus and Epocilla, Evarcha, Ganophosa, Sosticus, Storena, Nephila, Lecauge, Araneus, Tetraganatha, Lycosa, Oxyopes, Neoscona and Cyclosa are found unique and distinctly positioned in observation biplot and in familial level Zodariidae, Salticidae, Ganophosidae, Lycosidae, Cheriacanrhiidae, Tertragnathidae and Araneidae were found unique in observation biplot Same results are found in loading vectors in generic and familial level.

Similarly, the Principal component analysis method was used by Rosa et al. (2019) to study the diversity of soil spiders in land use and management systems in Santa Catarina, Brazil and evaluate the habitat specific occurrence of spider in native forest, eucalyptus reforestation, pasture, crop-livestock integration, and no-tillage crop. Schuldt et al. (2008) also used PCA to analyse ground-living communities of spiders in deciduous forests with relationship between spider diversity and ecosystem function in Thuringia.

\subsubsection{Correspondence analysis (CA)}

The ordination plot explains the occurrence of Arachnids in generic and familial level at observed ecosystems, in generic level CA asymmetric row plot explained total $67.26 \%$ of variation in which factor CA axis 1 and factor CA axis 2 explained $37.47 \%$ and $29.79 \%$ and in familial level asymmetric row plot explained total $84.91 \%$ of variation in which factor CA axis 1 and factor CA axis 2 explained $47.80 \%$ and $37.11 \%$ of variation respectively. The asymmetric row and column plot in generic level suggested that the genus Tylorida, Cyclosa, Neoga, Phintella, Hamadruas etc., Ruborridion, Clubiona, Guizygiella, Callilepis etc., Dorassodes, Nihohimea, Philodromus, Castineria, Dolomedes, Olios etc., Epocilla, Sosticus, Evarcha etc., Myrmarache, Larinis, Thaina, Mesida, Gasteracantha, Zelotes etc. showed affinity towards maize, rice, silvicultural, potato and horticultural ecosystems respectively. The asymmetric row and column plot in familial level showed that the family Cheiracanthiidae, Zodariidae, Pasauridae, Philodromidae, Pholcidae, Corinnidae, Salatcidae, Ganophosidae etc., showed a distinctive relation to Silviculture, horticultural and potato ecosystems. The family Linyphiidae, Aranidae, Tetraganthidae, Clubionidae, Mimentidae, Oxyopidae, Uloboridae etc., showed a relation to maize and rice ecosystems respectively.

This method was used by Forbanka and Niba (2013) to study the association of invertebrate to different site specific occurrence to habitat variables Viz., litter depth, grazing intensity, soil pH, soil phosphorus content and texture in forest ecosystems. Kosulic et al. (2016) used these methods to study the spider assembles and it association to canopy openness in forest ecosystems.

\subsection{Multivariate analysis of relationship between arthropods and environmental parameters}

\subsubsection{Redundancy Analysis (RDA)}

In rice ecosystem the families such as Clubionidae, Oxyopidae, Ulboridae and Mimetidae are strongly associated with morning relative humidity. The families Salticidae, Linyphiidae, Cheiracanthiidae and Zodariidae are found to associate with evening relative humidity and rainfall. In familial level the Arachnids population did not show any relationship to minimum temperature in maize and potato ecosystems. In silvicultural and horticultural ecosystems the arthropods orders Araneae, Dermptera, Colioptera, Dictyoptera, Neuroptera, and Isoptera showed a strong relation 
to maximum temperature. In rice ecosystem the orders Hymenoptera, Orthroptera, Odonata, Lepidoptera and Hemiptera showed strong association to morning relative humidity. In ordinal level the arthropods population did not show any relationship to minimum temperature, rainfall and evening relative humidity in maize and potato ecosystems.

Schuldt et al. (2008) used redundancy analysis (RDA) to study spider population and its association to environmental parameters viz., soil $\mathrm{pH}$, lime, litter depth, herb cover and soil moisture in Communities of groundliving spiders in deciduous forests and found no significant correlation of species richness and above environmental variables. Rosa et al. (2019) used redundancy analysis (RDA) to study spider population and its association to environmental parameters viz., organic matter, magnesium, resistance to root penetration, weighted mean diameter, microporosity, macroporosity, total organic carbon, aluminium, soil bulk density, calcium, biopores, nitrogen, soil moisture in western Santa Catarina, Mexico in winter and summer seasons.

\subsubsection{Canonical Correlation Analysis (CCA)}

\subsubsection{In Silvicultural ecosystem}

Canonical Correlation Analysis (CCA) map indicated that Arachnids families Lycosidae, Pholcidae, Zodariidae and Corinnidae etc. were closely associated with maximum temperature; Araneidae, Theridiidae, Linyphiidae and Salticidae associated with morning RH. The family Cheiracanthiidae, Clubionidae Philodromidae and Sparassidae were associated with evening $\mathrm{RH}$, rainfall and minimum temperature in familial level. The families Oxyopidae, Mimetidae and Tetraganthidae did not showe any relationship to environmental parameters. In ordinal level, orders Isoptera and Lepidoptera were strongly associated with maximum temperature and evening RH; Odonata and Hemiptera were associated with rainfall. The orders Ephimeroptera and Hymenoptera showed positive relationship towards environmental parameters i.e. minimum temperature and morning RH. The orders Dermeptera, Neuroptera, Dictyoptera, Orthoptera, Coleoptera etc. did not show any relationship to environmental parameters.

\subsubsection{In Horticultural ecosystem}

The Arachnids families Lycosidae, Clubionidae and Corinnidae etc. were closely associated with rainfall and evening RH; Salticidae and Thomisidae were associated with morning $\mathrm{RH}$ and rainfall. The family Cheiracanthiidae and Zodariidae were associated with maximum temperature in familial level. The families Oxyopidae, Theridiidae, Linyphiidae, Araneidae and Tetraganthidae did not show any relationship to environmental parameters. In ordinal level, orders Isoptera and Araneae were strongly associated with maximum temperature and Hemiptera with rainfall. The orders Lepidoptera and Coleoptera showed positive relationship to environmental parameters maximum temperature. The orders which are found in horticultural ecosystem did not show any association with morning and evening RH.

Maxim et al. (2005) evaluated the effects of a recent wildfire and clear cuts on ground-dwelling boreal forest spider assemblages and used canocical corrrelation analysis (CCA) to study association of spider assemblages (62 species) to environmental parameters (12 Nos.) in canopy, moss-lichen, Moss-lichen depth, ground vegetation, Litter depth, snags, leaves, bare soil, Heterogeneity index, stumps and tree fall. Forbanka and Niba (2013) studied the distribution and diversity of epigaeic invertebrate assemblages in Silaka Nature Reserve, Eastern Cape, South Africa with environmental variables grazing intensity, litter depth, soil phosphorus, soil $\mathrm{pH}$, percentage sand, percentage clay and percentage silt and found Geophilomorpha, Amphipoda, Isopoda and Opiliones prefers moist and humid habitat, Opiliones, Isopoda and Amphipoda associated with soil texture, $\mathrm{pH}$ and phosphorus content. Muhammad and Ahmed 
(2014) studied the seasonal abundance of soil arthropods in relation to meteorological and edaphic factors in the agroecosystems viz., sugarcane, cotton, wheat, alfalfa and citrus orchards of Faisalabad, Punjab, Pakistan and used Canocical Corrrelation Analysis (CCA) to study association of spider assemblages to environmental parameters and found Myriapoda correlated with soil temperature and soil organic matter although Collembola, Acarina and Araneae were correlated with relative humidity and soil organic matter composition. 


\section{References}

Aart PJM (van der) and Smeenk-Enserink N 1975, Correlations between distributions of hunting spiders (Lycosidae, Ctenidae) and environmental characteristics in a dune area, Neth. J. Zool., 25, 1-45

Barrian AT and Litsinger JA 1995, Riceland spiders of south and southeast Asia (CABI, Wallingford: CABI)

Birks HJB, Austin HA, Indrevaer NE, Peglar SM and Rygh C 1998, An annotated bibliography of canonical correspondence analysis and related constrained ordination methods, http://adn.biol.umontreal.ca/ numericalecology/index. html.

Birks HJB, Juggins S and Line JM 1990 Lake surface-water chemistry reconstructions from palaeolimnological data; in The surface waters acidification programme (eds) Mason BJ (Cambridge: Cambridge University Press) pp $301-13$

Bouseksou S, Kherbouche-Abrous O and Beladjal L 2015, Ecology of Araneae (Arthro poda, Arachnida) populations in two agroecosystems: wheat and oilseed rape in the Mitidja plain (Algeria), Life Environ., 65(4), 257-64

Cadoret LP, Legendre M, Adjeroud and Galzin R 1995, Spatial distribution of Chaetodontidae in different reef areas of Moorea Island, French Polynesia, Ecoscience, 2, 129-40

De'ath G 2002, Multivariate regression trees: a new technique for modeling species environment relationships, Ecol., $83,1105-17$

DeLong JrDC 1996, Defining biodiversity, Wildl. Soc. Bull., 24(4), 738-49

Fisher RA 1940, The precision of discriminant functions, Ann. Eugn., 10, 422-29

Forbanka DN and Niba AS 2013, Distribution and diversity of epigaeic invertebrate assemblages in Silaka Nature Reserve, Eastern Cape, South Africa, African Entomol., 21(1), 58-69

George WU, Juraj H and Alan BC 1999, Guild structure of spiders in major crops, J. Arachnol., 27, 270-80

Hatheway WH 1971 Contingency-table analysis of rain forest vegetation; in Statistical ecology. Many species populations, ecosystems and systems analysis (eds) Patil GP, Pielou EC and Waters WE (London: Pennsylvania State University Press) pp 271-13

Hill MO 1973 Reciprocal averaging: an eigenvector method of ordination, J. Ecol., 61, 237-49

Hirschfeld, H.O. (1935). A connection between correlation and contingency. Proc. Camb. Phil. Soc., 31: 520-524.

Ibanez F and Seguin G 1972, Study of the annual cycle of zooplankton of Abidjan. Comparison of several multivariate analysis methods: main components, correspondences, principal coordinates, Invest. Pesq., 36, 81-108

Joseph AR and Premila KS 2016, A study on the richness of spider fauna in rice ecosystem, J. Entomol. Zool. Stud., $4(2), 425-30$

Khan AA 2009, Biodiversity of spider fauna (Arachnida: Araneae) in horticultural ecosystem of Kashmir, J. Biol. Control., 25(2), 103-13

Khan AA and Khan ZH 2011 Spider fauna (Arachnida: Araneae) in horticultural ecosystem; in Animal Diversity, Natural History and Conservation (eds) Gupta VK (New Delhi: Daya Publishing House) pp 313-38.

Khan AA and Rather AQ 2012, Diversity and foraging behaviour of spider (Arachnida: Araneae) in the temperate Maize ecosystem of Kashmir, J. Biol. Control., 26(2), 179-89 
Kosulic O 2015, Spiders (Arachnida: Araneae) from forest ecosystems of Třesín national nature monument (litovelsképomoraví, czech republic) with suggestions to conservation management of the locality, Acta. Univ. Agric. et Silvic. Med. Bus., 63(3), 751-67

Kulczynski S 1928, The plant associations of pienins, Int. Bull. Pol. Acad. Sci. Lett. Ser. B Suppl. II, 57-203

Legendre P and Chodorowski A 1977, A generalization of Jaccard's association coefficient for $Q$ analysis of multistate ecological data matrices, Polish. J. Ecol., 25, 297-308

Legendre P and Legendre L 2012 Numerical Ecology, (Amsterdam: Elsevier)

Maxim L, Fahrig L and Drapeau P 2005, Effects of a recent wildfire and clear cuts on ground-dwelling boreal forest spider assemblages, Can. J. For. Res., 35(11), 2575-88

Muhammad MS and Ahmed S 2014, Seasonal abundance of soil arthropods in relation to meteorological and edaphic factors in the agroecosystems of Faisalabad, Punjab, Pakistan, Int. J. Biometeorol., 59(5), 605-16

Pinzon J, Spence JR and Langor DW 2011, Spider assemblages in the overstory, understory and ground layers of managed stands in the western boreal mixedwood forest of Canada, Environ. Entomol., 40(4), 797-808

Rao CR 1964, The use and interpretation of principal component analysis in applied research, Sankhyaa. Ser., 26, 32958

Rosa MG, Brescovit AD, Baretta CRDM, Santos JCP, Oliveira Filho LCI and Baretta D 2019, Diversity of soil spiders in land use and management systems in Santa Catarina, Brazil, Biota. Neotropica., 19(2), 1-10

Roux G and Roux M 1967, About some classification methods in phytosociology, Rev. Stat. Appl., 15, 59-72

Samu F, Sunderland KD and Szinetar C 1999, Scale-dependent dispersal and distribution patterns of spiders in agricultural systems: a review, J. Arachnol., 27(1), 325-32

Saranya VSL, Samiayyan K and Prema MS 2019, Diversity of predatory spider fauna in maize ecosystem, J. Biol. Control., 33(1), 27-35

Schuldt A, Fahrenholz N, Brauns M, Migge-Kleian S, Platner C and Schaefer M 2008, Communities of ground-living spiders in deciduous forests: Does tree species diversity matter?, Biodivers. Conserv., 17, 1267-84

Sidclay CD, Leonardo SC, Bonaldoa AB and Brescovitc AD 2010, Refining the establishment of guilds in Neotropical spiders (Arachnida: Araneae), J. Nat. Hist., 44(3-4), 219-39

Sorensen T 1948, A method of establishing groups of equal amplitude in plant sociology based on similarity of species content and its application to analyses of the vegetation on Danish commons, Biol. Writ., 5, 1-34

Swingland IR 2001 Biodiversity, definition of; in Encyclopedia of biodiversity (eds) Levin SA (California: Academic Press) pp 377-91

Ter Braak CJF 1986, Canonical correspondence analysis: a new eigenvector technique for multivariate direct gradient analysis, Ecol., 67, 1167-79

Thorrington-Smith M 1971, West Indian Ocean phytoplankton: a numerical investigation of phytohydrographic regions and their characteristic phytoplankton associations, Mar. Biol., 9, 115-37

Tikader BK 1987 Hand book of Indian spiders (Calcutta: The director, zoological survey of India) 
Tikader BK and Bal A 1980, Studies on spiders of the genus Zygeilla Cambridge from India (Araneae: Araneidae). Proceedings of the Indian Academy of Science (Anim. Sci.), Pp.243-246, May 1980, Bangaluru, India

Tim MZ and Roth M 2008, Influence of environmental parameters on small-scale distribution of soil-dwelling spiders in forests: What makes the difference, tree species or microhabitat?, For. Ecol. Manag., 255(3-4), 738-52

Wollenberg van den AL 1977, Redundancy analysis. An alternative for canonical correlation analysis, Psychomot., 42, 207-19 
Figures

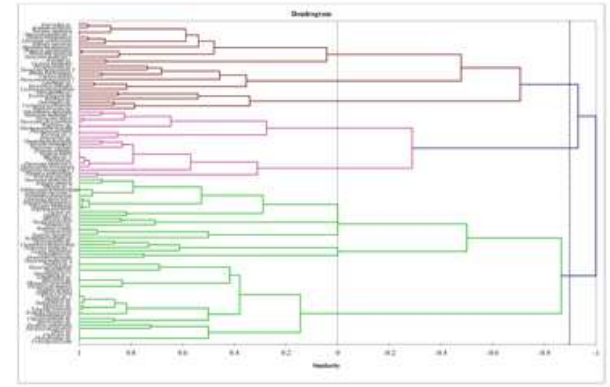

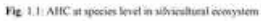

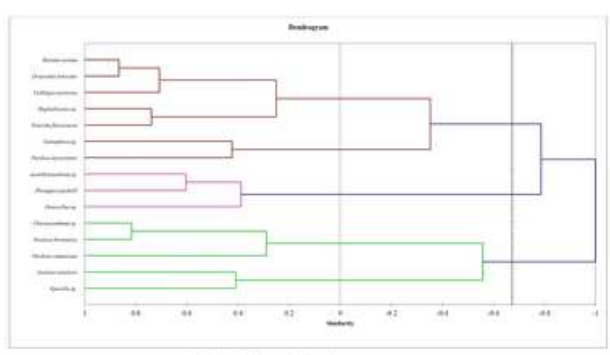

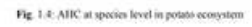

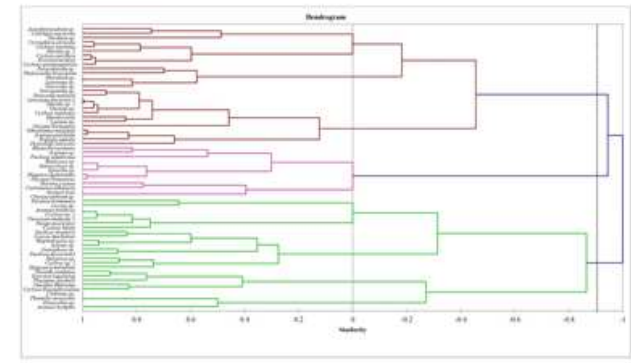

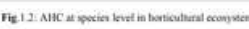

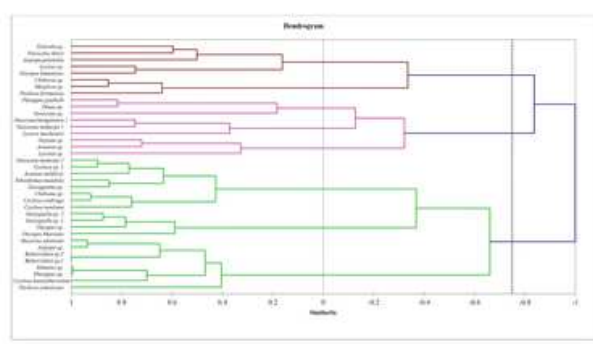

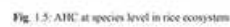

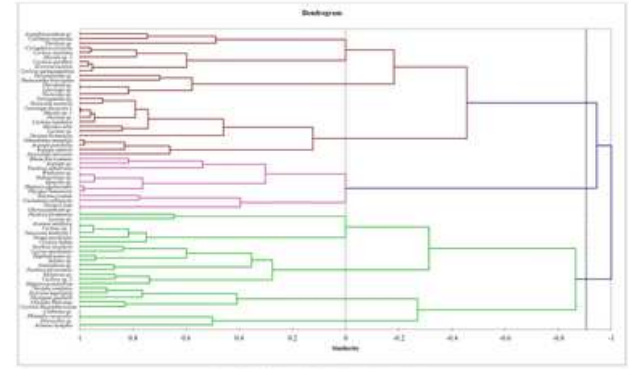

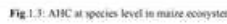

\section{Figure 1}

Please see the Manuscript PDF file for the complete figure caption

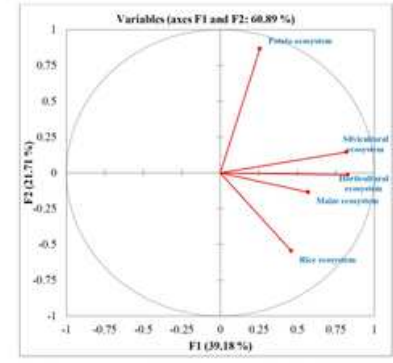

Fig. 2.1: Principal component analysis (PCA) scree plot for spider fanilies in observed

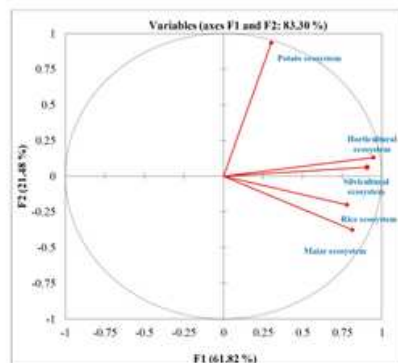

Fig 2.2: Principal component analysis (PCA) sctee plot for spider genera in observed

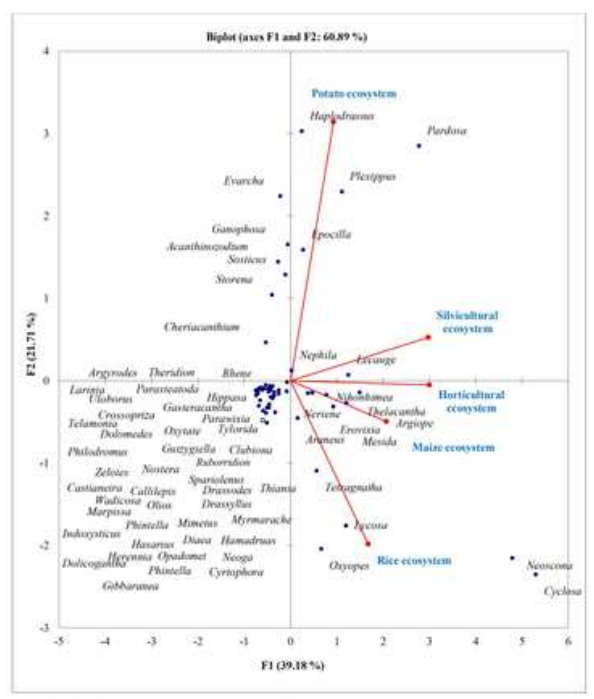

Fig. 2.3. Principal component analysis (PCA) biplot for spider genera (in italics) and observed ecosystens (in blue)

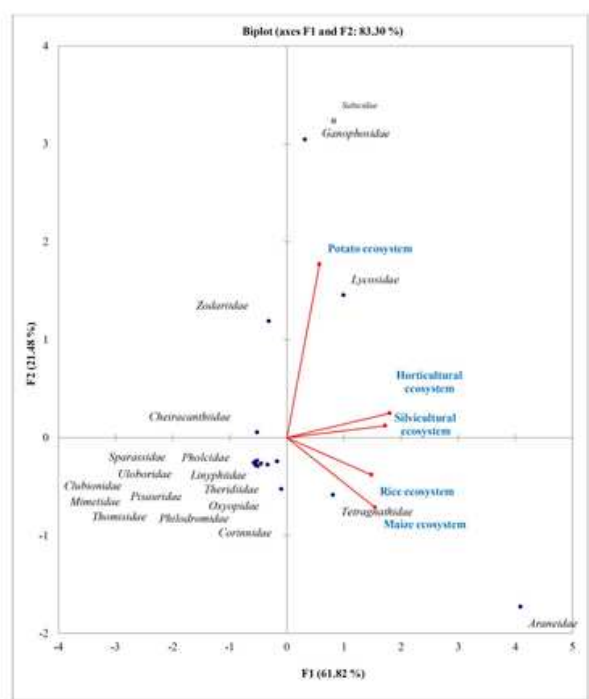

Fig. 2.4: Principal conponent analysis (PCA) biplot for spider orders and observed ecosystems (in blue)

Figure 2

Please see the Manuscript PDF file for the complete figure caption 

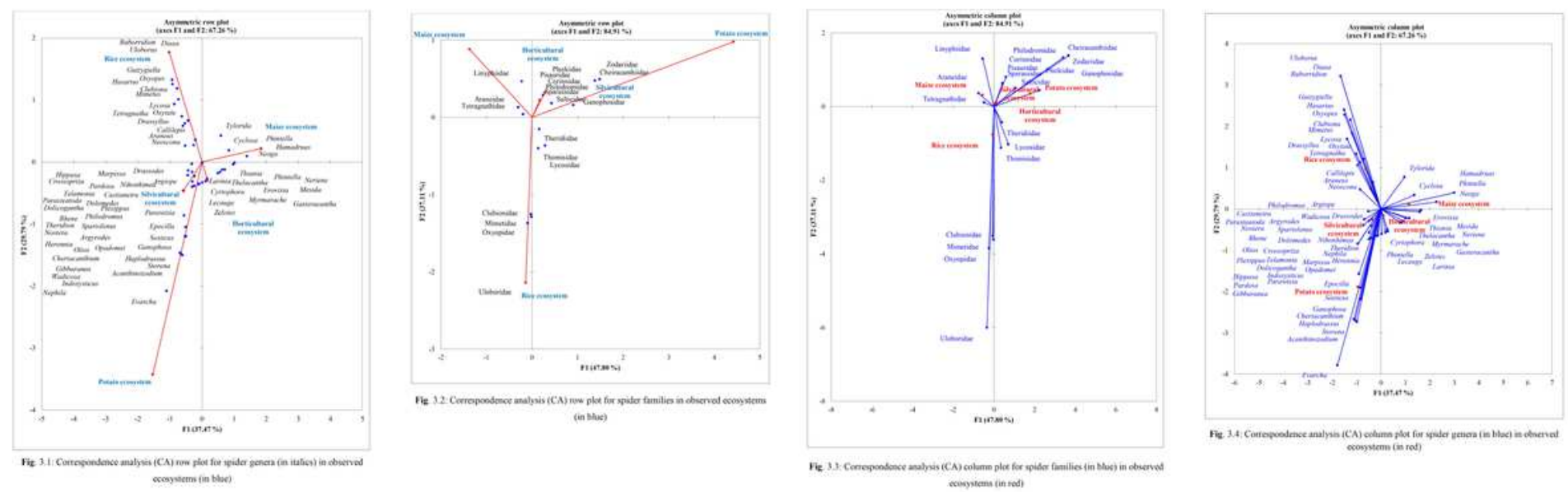

\section{Figure 3}

Please see the Manuscript PDF file for the complete figure caption

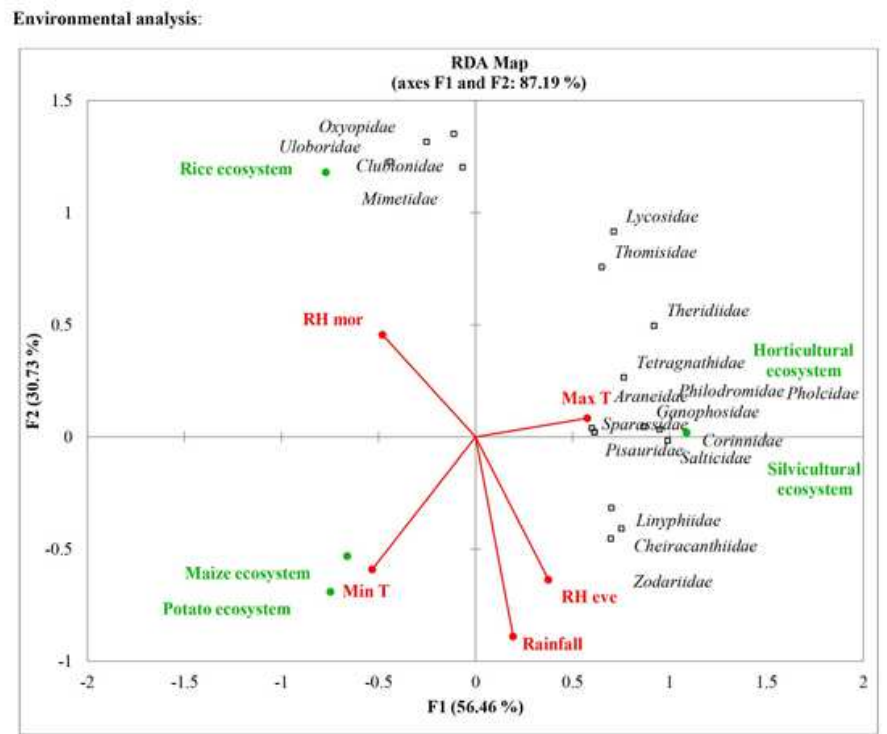

Fig. 4.1: Redundancy analysis (RDA) for arthropods family and environmental parameters (in red) in observed ecosystems (in green)

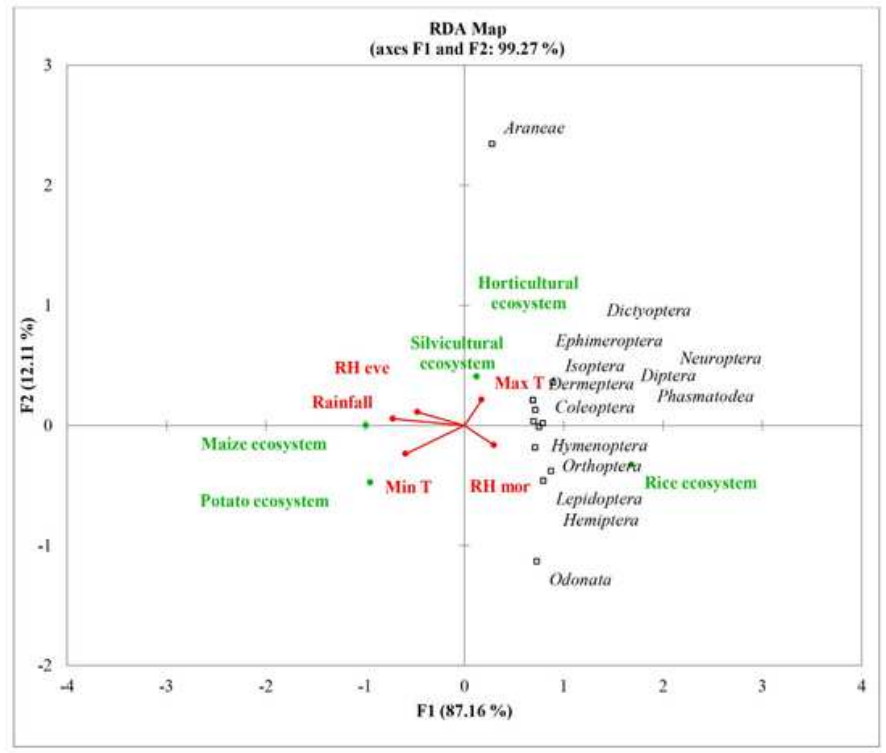

Fig. 4.2: Redundancy analysis (RDA) for arthropods orders and environmental parameters (in red) in observed ecosystems (in green)

\section{Figure 4}

Please see the Manuscript PDF file for the complete figure caption 

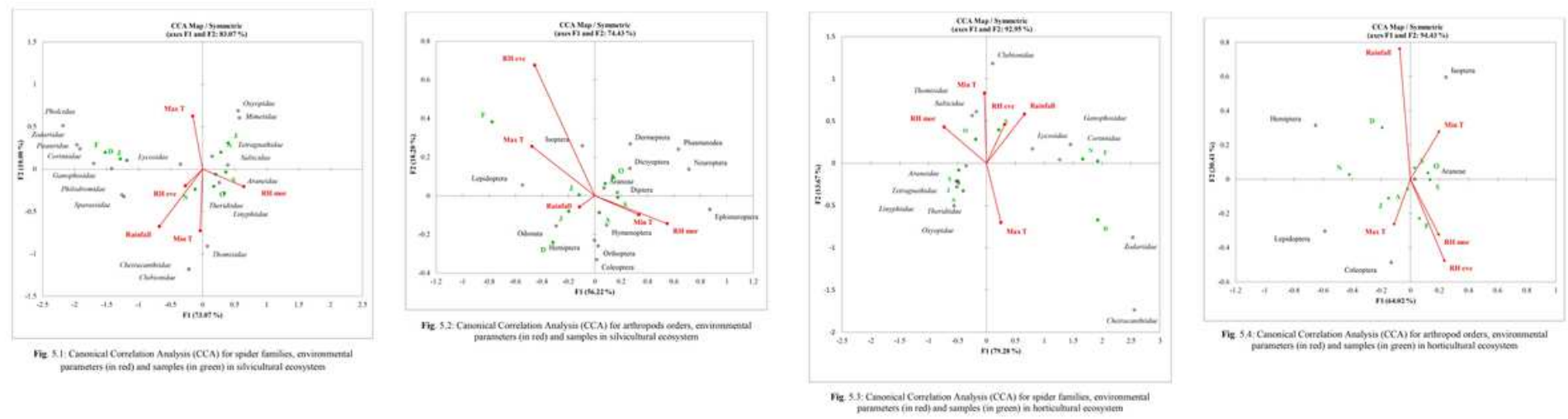

Figure 5

Please see the Manuscript PDF file for the complete figure caption

\section{Supplementary Files}

This is a list of supplementary files associated with this preprint. Click to download.

- Tables.pdf 